\title{
Meatloaf with Semi-dry Vegetables: A Study of Processing and Preservation
}

\author{
Incoronato AL, Conte A, Gammariello D and Del Nobile MA*
}

Service Center for Applied Research, University of Foggia, via Napoli, 25-71122 Foggia, Italy

\begin{abstract}
This study evaluated the synergic effects of MAP, essential oils (nutmeg and laurel) and Na-lactate on shelf-life extension of a ready-to-cook fresh meal based on meatloaf and semi-dried vegetables. Microbial and sensory qualities, $\mathrm{pH}$ and gas composition were assessed during the storage at $4^{\circ} \mathrm{C}$. Surface treatments of meat with $\mathrm{Na}$-lactate solution alone or combined with the essential oils, under MAP, increased the shelf life to more than 5 and 7 days, respectively, compared to the control that remained acceptable for about 2 days. Both treatments were effective in suppressing spoilage bacteria, maintaining good surface color and preventing development of off-odor
\end{abstract}

Practical application: The current work represents an interesting study to develop new convenience food based on meat and vegetables with proper shelf life. The technology to realize the product was presented and some simple preservation strategies able to prolong the shelf life are also proposed. Both microbial and sensory quality were taken into account during storage, thus giving more detailed information on main quality factors that are responsible for product acceptability.

Keywords: Antimicrobial compounds; MAP; Meat; Ready-to-cook meal; Shelf life

\section{Introduction}

The meat loaf is a typical dish with an European origin. Meatloaf is made up of ground meat mixed with other ingredients, formed into a loaf shape, then baked or smoked. Meatloaf is usually made from ground beef, although pork, veal and poultry can be also used. The meatloaf is mainly distributed by the industry as whole piece but it can be possible to display meat slices packed in family-sized portions as ready-to-cook product. Slices preparation involves manipulation, and generally handling of food product can provoke contamination from the environment, handlers, equipment, and so forth. An additional problem is the temperature abuse which could occur during distribution, thus interrupting the refrigerated chain. Meat can be compromised by a large number of pathogenic and spoilage microorganisms during primary and further processing [1]. The contamination of sterile animal muscle is a direct consequence of slaughtering and dressing of animal carcasses. Wide ranges of microorganisms from different sources are transferred on meat surfaces that are rich in nutrients and becomes good substrate for microbial proliferation.

The number of microorganisms on fresh meat surfaces changes during chill storage following a typical microbial growth pattern. Counts of bacteria in meat are in the range of $10^{2}-10^{5} \mathrm{cfu} / \mathrm{cm}^{2}$, but only around $10 \%$ are able to grow. The initial lag phase is attributed to microbial adaptation to changing conditions (chill temperatures and surface desiccation). Ensuing logarithmic growth takes place after cells have accommodated to the new environmental setting and adapted their metabolism. When numbers exceed $10^{7}$ cells per $\mathrm{cm}^{2}$, the first spoilage signs are detected as off-odors. With respect to health and economic problems caused by these bacteria, it is very important to reduce the initial microbial population on meat. Sanitization of meat surfaces prior to grinding or prior to the production of batters may improve the control of food-borne pathogens or spoilage microorganisms. Various strategies have been developed to reduce the level of bacteria on surface of animals' carcass, such as washing and sanitizing with hot water, chlorinated water, food grade acids and salts [2].
Other studies have been carried out to optimize the technologies in different kind of meats, as beef, pork and poultry. Thus, applications of electrolyzed oxidizing water [3], high pressure in combination with antimicrobials [4], and surface sanitizers such as chlorine dioxide, cetyl-pyridinium chloride, and lactic acid $[5,6]$ could extend shelf life of meats. Another surface treatment that is known to improve shelf life is the dipping in solutions of natural compounds. Compounds of plant origin and organic acid solutions or their salts actually appear to be the most promising means to control meat decay, above all when these techniques are used in combination with modified atmosphere packaging (MAP). The synergic effects of water-soluble rosemary extract and MAP on sensory and microbiological extension of turkey meatballs was also investigated by Karpinska-Tymoszyk [7]. The addition of rosemary extract gave rise to an improvement of sensory quality, in particular when stored under modified atmosphere. An increase of the preservative effect of MAP and essential oils (Laurus nobilis) has been shown in round chicken breast meat stored at $4^{\circ} \mathrm{C}$ [8]. Zeitoun [9] found the synergistic effect of MAP, lactic acid and sodium lactate antimicrobial activity on fresh chicken legs. Gammariello et al. $[10,11]$ demonstrated that the combined effect of sodium lactate and MAP improved the shelf-life of ready-to-cook fresh skewer, made up of turkey meat. The salt of lactate is frequently used as an antimicrobial in meat products, due to its beneficial properties when applied at appropriate concentrations. The addition of lactate to food products with neutral $\mathrm{pH}$ offers good prospects for shelf-life prolongation. In general, Gram-positive bacteria were more sensitive toward lactate

*Corresonding author: Matteo Alessandro Del Nobile, Service Center for Applied Research, University of Foggia, via Napoli, 25-71122 Foggia, Italy, Tel: +39 0881 589 242; E-mail: matteo.delnobile@unifg.it

Received July 07, 2015; Accepted July 28, 2015; Published August 04, 2015

Citation: Incoronato AL, Conte A, Gammariello D, Del Nobile MA(2015) Meatloaf with Semi-dry Vegetables: A Study of Processing and Preservation. J Food Process Technol 6: 470. doi:10.4172/2157-7110.1000470

Copyright: (C) 2015 Incoronato AL, et al. This is an open-access article distributed under the terms of the Creative Commons Attribution License, which permits unrestricted use, distribution, and reproduction in any medium, provided the original author and source are credited. 
than Gram-negative bacteria under optimum growth conditions ( $\mathrm{pH}$ $6.5,20^{\circ} \mathrm{C}$ ) [12]. In this context, research on the effects of MAP in combination with natural compounds on the quality of ready-to-cook meat products is still limited. Therefore, the objective of this study is to evaluate the effect of MAP and addition of laurel, nutmeg and sodiumlactate on the microbiological and sensory characteristics of ready-tocook meal during chilled storage.

\section{Materials and Methods}

\section{Samples preparation}

The ready-to-cook meal was made up at laboratory scale with pork ham as meatloaf with semi-dried vegetables (artichokes, peppers and tomatoes). Sodium-lactate (Na-lactate, sodium salt of lactic acid, $60 \%$ w/w) (Giusto Faravelli Spa, Milano, Italy) was used to pre-treat meat before processing and different MAP were applied during packaging. Meat was provided by a meat company, Dodaro Spa (Spezzano Albanese, Cs, Italy) and transported to the laboratory in polystyrene boxes with an appropriate quantity of flaked ice. Semi-dry vegetables were purchased from a local company, Fiordelisi (Fiordelisi srl, Stornarella, Fg, Italy), and transported to the laboratory in boxes. The meat pieces, prior to grinding, were subjected to two treatments by dipping. In a first step, meat samples were cut into small cubes (approximately 30-40 $\mathrm{g}$ ), and were dipped for $10 \mathrm{~min}$ in pre-chilled $\left(4^{\circ} \mathrm{C}\right)$ aqueous solution of Na-lactate at the concentration of $60 \%(w / w)$. After treatment, meat samples were drained for $5 \mathrm{~min}$ at ambient temperature $\left(20^{\circ} \mathrm{C}\right)$. In a second step, Nutmeg and Laurel essential oils (Farmalabor s.r.l., Canosa di Puglia, BAT, Italy) were dissolved in $100 \mathrm{~mL}$ of extra-virgin olive oil (EVO) at the concentration of $1.25 \mathrm{~g} / 100 \mathrm{~mL}$ and $2.5 \mathrm{~g} / 100 \mathrm{~mL}$, respectively. The applied amount of solutions was $10 \%$ referred to the meat weight (1 kg meat/100 mL solution of EVO and essential oils). Solutions of EVO and essential oils were completely absorbed by the meat samples, while the amount not absorbed was mixed to the meat as an ingredient. No treated samples were used as reference.

Once antimicrobial treatments were completed, meat cubes were ground separately. Before use, all metal parts of the meat grinder were dipped in aqueous solution of Na-lactate $(60 \% \mathrm{w} / \mathrm{w})$ for $25 \mathrm{~min}$. The ground meat was prepared by mixing for 4-5 minutes all the ingredients with a food processor in the following amounts: sodium chloride (1\%), Parmigiano-Reggiano cheese (3\%), grated bread (3.5\%), garlic $(0.03 \%)$, parsley $(2 \%)$ and white bread (10\%) with the addition of milk $(20 \%)$ and essential oils. The dough meat was spread on a sheet of baking paper ( $1 \mathrm{~cm}$ thickness) and was distributed on the surface of the semi dried vegetables previously seasoned $(1 \mathrm{Kg}$ of dough meaty/300 g of vegetables); subsequently, the meatloaf was sliced obtaining slices of 1.5-2 $\mathrm{cm}$ thickness. Artichokes, peppers and tomatoes were seasoned with sodium chloride $(1,6 \% \mathrm{w} / \mathrm{w})$, garlic $(1 \% \mathrm{w} / \mathrm{w})$, parsley $(1 \% \mathrm{w} / \mathrm{w})$ and extra-virgin olive oil $(33,3 \% \mathrm{w} / \mathrm{w})$. The seasoned vegetables were left at room temperature with intermittent agitation for at least $2 \mathrm{~h}$, to allow the uniform distribution of the ingredients.

Each seasoned meat slice was packaged in bag hermetically sealed by means of an S100-Tecnovac equipment (Tecnovac, Bergamo, Italy) under MAP and stored at $4^{\circ} \mathrm{C}$. The bags were $220 \times 320 \mathrm{~mm}$ long, and constituted by an anti-fog high-barrier multilayer film provided by Di Mauro (Officine Grafiche spa, Salerno, Italy). To realize MAP, the following gas concentrations were used: $30: 70 \mathrm{CO}_{2}: \mathrm{N}_{2}$.

The treatments applied were namely as follows: CNT-MA (slices of meatloaf without dipping and packaged under MAP); SL60-MA (slices of meatloaf dipped with $60 \% \mathrm{Na}$-lactate solution and packaged under
MAP); EO-MA (slices of meatloaf dipped with mix of essential oils and packaged under MAP); SL60-EO-MA (slices of meatloaf dipped with $60 \%$ Na-lactate solution and essential oils solution and packaged under MAP).

The samples were withdrawn at regular intervals for microbiological and sensory evaluation, $\mathrm{pH}$ measurements and gas monitoring.

\section{Gas composition of the package headspace}

Prior to opening the bags, headspace gas composition was determined by using a Checkmate 9900 gas analyzer (PBI Dansensor, Ringsted, Denmark). The volume taken from the package headspace for gas analysis was about $10 \mathrm{~cm}^{3}$. To avoid modifications in the headspace gas composition due to gas sampling, each package was used only for a single determination of the headspace gas composition. Three bags were used for each analysis.

\section{Microbiological analyses and $\mathrm{pH}$ determination}

Samples of $25 \mathrm{~g}$ (each consisting of equal amounts of both meat and vegetable pieces) were aseptically removed from the bags transferred into a stomacher bag and homogenized for $3 \mathrm{~min}$ (Stomacher LAB Blender 400, Pbi International, Milan, Italy) with $225 \mathrm{ml}$ of sterile peptone solution (Oxoid, Milan, Italy). Further decimal serial dilutions were prepared from this homogenate in the same sterile diluent and these were subsequently used for enumeration and differentiation of microorganisms. Total aerobic bacteria (TAB) were determined using Plate Count Agar after incubation for $48 \mathrm{~h}$ at $30^{\circ} \mathrm{C}$. Pseudomonas spp. were enumerated on Pseudomonas Agar Base supplemented with cetrimide, fucidine and cephaloridine (CFC) supplements providing a selective isolation medium for Pseudomonas spp. Colonies were counted after $48 \mathrm{~h}$ at $25^{\circ} \mathrm{C}$. Lactic Acid Bacteria (LAB) were enumerated by the pour plating technique on de Man Rogosa Sharpe agar and incubated under anaerobiosis at $30^{\circ} \mathrm{C}$ for $48 \mathrm{~h}$. Enterobacteriaceae counts were enumerated by the pour plating technique on Violet Red Bile Glucose Agar after incubation at $37^{\circ} \mathrm{C}$ for $24 \mathrm{~h}$. Media and supplements for the microbiological analyses were procured from Oxoid (Milan, Italy) The microbiological analyses were carried out twice on two different batches. The results were expressed as the logarithm of the colony forming units for gram $(\log \mathrm{cfu} / \mathrm{g})$.

In order to determine the microbiological acceptability limit (MAL defined as the time at which the microbial loads reached the maximum value permitted), the re-parameterized version of the Gompertz equation was fitted to the total aerobic bacterial data (TAB), according to a similar approach also used in previous works dealing with shelf life of meat $[13,14]$. In particular, the following equation (1) was used to calculate the MAL:

$$
\begin{aligned}
& \log (N(t))=\log \left(N_{\max }\right)-A \cdot \exp \left\{-\exp \left\{\left[\left(\mu_{\max } \cdot 2 \cdot 71\right) \cdot \frac{\lambda-M A L}{A}\right]+1\right\}\right\}+1^{-\exp } \\
& +A \cdot \exp \left\{-\exp \left\{\left[\left(\mu_{\max } \cdot 2 \cdot 71\right) \cdot \frac{\lambda-t}{A}\right]+1\right\}\right\}
\end{aligned}
$$

where $\mathrm{N}(\mathrm{t})$ is the viable cell concentration (CFU/g) at storage time $t, A$ is related to the difference between the decimal logarithm of maximum bacterial growth attained at the stationary phase and the decimal logarithm of the initial cell load concentration (CFU/g), $\mu_{\max }$ is the maximal specific growth rate $(\Delta \log [\mathrm{CFU} / \mathrm{g}] /$ day $), \lambda$ is the lag time (day), $\mathrm{t}$ is the time (day), $\mathrm{N}_{\text {max }}$ is the threshold value (CFU/g), MAL is the microbial acceptability limit (day) (i.e., the storage time at which the $\mathrm{N}\left(\mathrm{t}\right.$ ) equals $\mathrm{N}_{\max }$ ). For TAB count the critical limit was set to $5 \times 10^{6}$ 
cfu/g, according to the 94/65 EC and 2073/2005 EC regulations.

The $\mathrm{pH}$ values were recorded on each sampling day using a pH meter (Crison Instruments model 2001, Barcelona, Spain). The $\mathrm{pH}$ determination, conducted twice, was performed on the first homogenized dilution of each sample.

\section{Sensory analysis}

A panel of seven experienced judges was used to evaluate colour, odour and overall quality of ready-to-cook meal samples on an 8-point scale [15]. Samples with a score equal or higher than 4 were considered acceptable. A re-parameterized Gompertz equation was fitted to the sensory data $[13,14]$ to allow calculating the sensory acceptability limit (SAL), defined as the time at which the overall quality of product reached the threshold (score $=4$ ). SAL:

In particular, the following equation (2) was used to calculate the

$$
\begin{aligned}
& O S Q(t)=O S Q_{\min }-A^{Q} \cdot \exp \left\{-\exp \left\{\left[\left(\mu_{\max }^{Q} \cdot 2 \cdot 71\right) \cdot \frac{\lambda^{Q}-S A L}{A^{Q}}\right]+1\right\}\right\}+ \\
& +A^{Q} \cdot \exp \left\{-\exp \left\{\left[\left(\mu_{\max } Q \cdot 2 \cdot 71\right) \cdot \frac{\lambda^{Q}-t}{A^{Q}}\right]+1\right\}\right\}
\end{aligned}
$$

where $\mathrm{OSQ}(\mathrm{t})$ is the overall sensory quality at time $\mathrm{t}, \mathrm{A}^{\mathrm{Q}}$ is related to the difference between the sensorial attribute attained at the stationary phase and the initial value of sensorial attribute, is the maximal rate at which OSQ $(\mathrm{t})$ decreases, $\lambda^{\mathrm{Q}}$ is the lag time, $\mathrm{OSQ}_{\min }$ is sensory threshold, $\mathrm{SAL}$ is the sensorial acceptability limit (i.e., the time at which OSQ $(t)$ is equal to $O S Q_{\text {min }}$ ), and $t$ is the storage time. As reported above, the value of $O_{\text {S }}$ in equal to 4 .

\section{Shelf life calculation}

The shelf life was calculated as the lowest value between MAL and SAL. In fact, it is the time at which one of the meat quality sub-indices reaches its threshold [14].

\section{Statistical analysis}

The fitting parameters were compared by one-way Anova analysis. The Tukey's test was used to determine significance among differences $(\mathrm{P}<0.05)$. To this aim, Statistica 7.1 for Windows 152 (StatSoft Inc., Tulsa, OK, USA) was used.

\section{Results and Discussion}

\section{Microbiological quality of meatloaf with semi-dried vegetables}

Figure 1 shows the viable cell concentration of TAB plotted as a function of storage time for all samples. The curves were obtained by fitting the experimental data, whereas the horizontal solid line is the viable cell concentration threshold. The MAL values, obtained according to the procedure reported in the Materials and Methods section, were listed in Table 1. Data highlight that MAL was affected by the synergy approach. In fact, the presence of essential oils alone did not affect significantly the MAL, while the dipping of Na-lactate and essential oils in synergy with MAP inhibited the cell load of TAB. As can be inferred from the figure, while the viable cell concentration of the CNT-MA sample went above the selected threshold $\left(5 \times 10^{6}\right.$ $\mathrm{cfu} / \mathrm{g}$ for TAB) already after more than 2 days, the treatments with Na-lactate provoked a significant reduction in microbial growth. The initial microbial load ranged from $5.90 \mathrm{log} \mathrm{cfu} / \mathrm{g}$ in the CNT-MA to $4.97 \log \mathrm{cfu} / \mathrm{g}$ in SL60-EO-MA. This indicates that the synergistic effect of treatments significantly delayed the rate of microbial growth and extended the shelf life of the ready-to-cook product. For meat products, microbial contamination occurs at the surface. The use of sanitizing agents or antimicrobial to decontaminate meat surfaces has been proved in the literature [16]. Vander marel et al. [17] investigated the effect of immersing carcasses in lactic acid for 15 seconds at various stages of processing on surface TPC, total psychrophiles, Enterobacteriaceae and $S$. aureus, as well as their growth at $0^{\circ} \mathrm{C}$ for 23 days. They reported that immediately after treatment the colonization was generally reduced by $1 \log$. In the specific case, all investigated samples treated with $\mathrm{Na}-$ lactate showed a significant prolongation of the microbial lag phase, as well as a substantial log reduction of about 1 cycle in comparison with the control sample. Indeed, treated samples recorded a MAL value of 8 for SL60-MA and 10.22 days for SL-60-EO-MA, respectively. The presence of EO reduced the initial population of TBA until the $2^{\text {nd }}$ day of storage when compared to the CNT-MA sample. Successively, the cell load of EO-MA exceeded the maximal value recommended, thus giving a MAL value of about 3 days. It has been documented that $\mathrm{Na}$ lactate has the ability to extend shelf-life of meat products. There are three proposed mechanisms by which the sodium lactate ion can have an antimicrobial affect; the first is the change of water activity (aw), the second is the sodium lactate passing through the cell membrane and lowering intracellular $\mathrm{pH}$, and the third one is the inhibition of ATP generation to affect cellular metabolism $[18,19]$.

With regard to Pseudomonas spp. (data not shown), while there was a decrease in cell load of treated samples during the first 5 days of storage followed by a slight increase at the end of the storage, the CNT-MA showed a gradual growth. Concerning Enterobacteriaceae growth (data not shown) for all samples there were rather irregular trends during the early days of observation. The initial count of microorganisms was approximately 2.72 and $2.91 \mathrm{log} \mathrm{cfu} / \mathrm{g}$ for EOMA and SL-60-EO-MA, respectively, whereas the CNT-MA (1.45 log $\mathrm{cfu} / \mathrm{g})$ and SL60-MA (1.39 log cfu/g) showed low Enterobacteriaceae contamination. At storage day 2 however, significant lower count was detected in samples treated with Na-lactate (1.93 in SL60-MA and 1.75 $\log \mathrm{cfu} / \mathrm{g}$ in SL-60-EO-MA) when compared with CNT-MA (2.30) or EO-MA (2.32 log cfu/g). Successively, all samples showed a slight increase, except for SL-60-EO-MA that showed a decrease with a final microbial load of about $1.15 \mathrm{cfu} / \mathrm{g}$. This result might have been due to the synergistic effect of the approach used. Data published in the available literature also demonstrate the antimicrobial effect of $\mathrm{Na}$ lactate on both Enterobacteraiaceae and Pseudomonas spp. [20].

With regard to $\mathrm{LAB}$ there was a slight decrease in the initial count of the treated samples (Figure 2). After the first day, there were no marked differences between the CNT-MA and EO-MA, whereas for SL60-MA and SL-60-EO-MA was observed a period of stability at the beginning, followed by an increase in cell numbers after the second day. Afterwards, the growth of LAB reached the stationary phase with a cell count similar to that of the CNT-MA. However, a combination of Na-lactate, essential oil and MAP appeared to be the most effective among the other single treatments against LAB growth. It has been documented that $\mathrm{Na}$-lactate is also effective against LAB in meat products $[21,22]$. Conversely, it has been reported that LAB dominated the microbial flora in NA-lactate treated beef during vacuum-packaged storage at $0^{\circ} \mathrm{C}[23]$.

\section{$\mathrm{pH}$ and headspace gas composition}

Changes in $\mathrm{pH}$ values of the ready-to-cook product during 


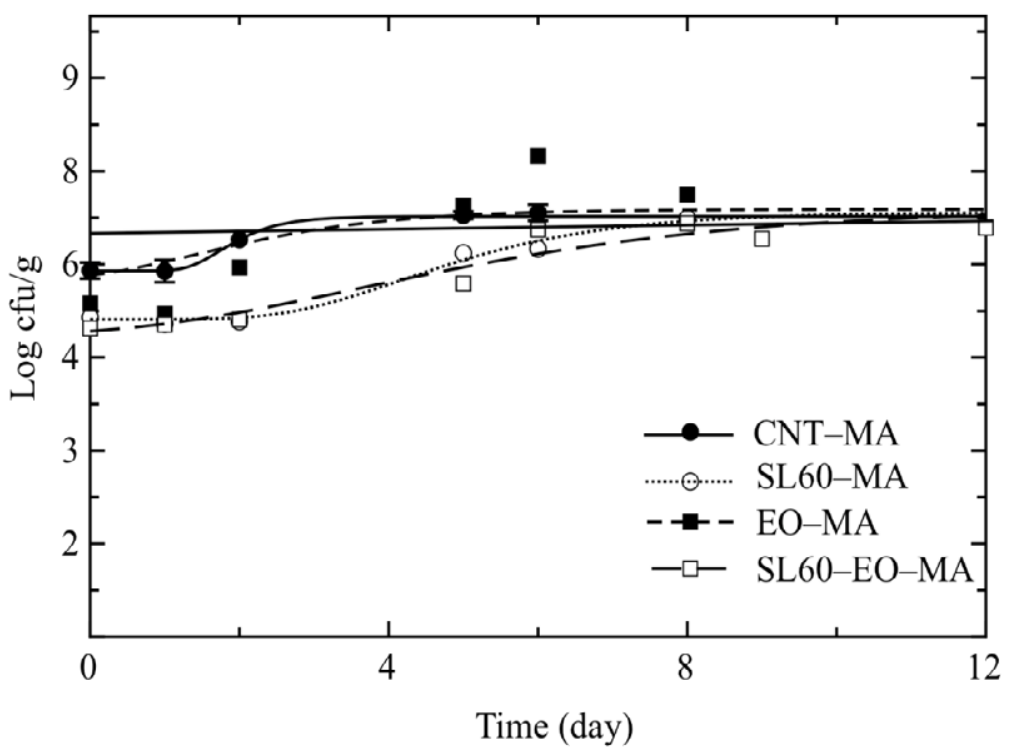

The curves are the best fit to the experimental data. CNT-MA(control sample packaged in MAP); EO-MA (sample treated with essential oils, packaged in MAP); SL60-MA (sample treated with Na-lactate 60\%, packaged in MAP); SL60-EO-MA (sample treated with Na-lactate 60\% and essential oils, packaged in MAP).

Figure 1: Evolution of total aerobic bacteria during the storage time.

\begin{tabular}{|c|c|c|c|}
\hline Samples & $\begin{array}{c}\text { MAL } \\
\text { (day) }\end{array}$ & $\begin{array}{c}\text { SAL } \\
\text { (day) }\end{array}$ & $\begin{array}{c}\text { Shelf life } \\
\text { (day) }\end{array}$ \\
\hline CNT-MA & $2.821 .96^{\mathrm{a}}$ & $4.94 \pm 0.39^{\mathrm{a}}$ & $2.82 \pm 1.96^{\mathrm{a}}$ \\
\hline EO-MA & $3.04 \pm 1.76^{\mathrm{a}}$ & $5.39 \pm 0.21^{\mathrm{ab}}$ & $3.04 \pm 1.76^{\mathrm{a}}$ \\
\hline SL60-MA & $8.03 \pm 1.65^{\mathrm{b}}$ & $5.93 \pm 0.17^{\mathrm{b}}$ & $5.93 \pm 0.17^{\mathrm{b}}$ \\
\hline SL60-EO-MA & $10.23 \pm 2.40^{\mathrm{b}}$ & $7.07 \pm 0.45^{\mathrm{c}}$ & $7.07 \pm 0.45^{\mathrm{c}}$ \\
\hline
\end{tabular}

${ }^{a-c}$ Data in the column with different superscript letters are significantly differen $(\mathrm{P}<0.05)$

Table 1: Microbial acceptability limit (MAL), sensory acceptability limit (SAL) and shelf life (mean $\pm S D$ ) of ready-to-cook meal.

storage at $4^{\circ} \mathrm{C}$ revealed that the initial $\mathrm{pH}$ value of CNT-MA (6.10) was higher than those of samples treated with EO (5.86), Na-lactate (5.79) or combination of Na-lactate and EO (5.66) (data not shown). Successively, the $\mathrm{pH}$ values of samples treated with $\mathrm{Na}$-lactate remained relatively constant throughout the rest of the study period, while the $\mathrm{pH}$ of CNT-MA and EO-MAP samples significantly decreased. These findings disagree with Eckert et al. [24] and Tan and Shelef [25], who reported that $\mathrm{NaL}$ had no significant effects on initial $\mathrm{pH}$ of ground meat products. In addition, these results are consistent with Sallam and Samejima [26], who found that addition of Na-lactate maintained the ground beef at almost constant $\mathrm{pH}$, while the $\mathrm{pH}$ of control or $\mathrm{NaCl}$ treated samples significantly decreased. Na-lactate was reported to have neutral $\mathrm{pH}$ during storage of meat products and is used as a $\mathrm{pH}$ control agent $[23,27,28]$.

The headspace atmosphere (data not shown) has undergone minor changes during the storage period and showed a slight fluctuation for all the samples under MAP. In general, the $\mathrm{CO}_{2}$ concentration of samples treated with Na-lactate steady decreased, whereas for the reference samples showed a gradual decline until the second day of observation, following by a rapid increase along the storage period. The $\mathrm{CO}_{2}$ concentration in EO-MA was slightly lower with respect to that of sample without any treatments. These findings were expected and are in agreement with what found by Esmer et al. [29] who noted that the changes of gas composition might be due to microbial growth, permeability of packaging material and gas absorption by the meat. Jakobsen and Bertelsen [30] also reported that the decrease of $\mathrm{CO}_{2}$ in MAP was the result of the absorption of $\mathrm{CO}_{2}$ into the meat. Nychas [2] concluded that during storage, some microorganisms in the meat utilized the $\mathrm{O}_{2}$ in the headspace of tray while some microflora, particularly $\mathrm{LAB}$, produce $\mathrm{CO}_{2}$. Conversely, the trend of the $\mathrm{N}_{2}$ is inverse to that of the $\mathrm{CO}_{2}$ for all samples. In terms of food spoilage, $\mathrm{N}_{2}$ is an inert gas, not reactive with meat pigments, not absorbed by the meat and tasteless, without any antimicrobial activity. It is not very soluble in water, and it is primarily used to displace oxygen and prevent package collapse [31].

\section{Sensory evaluation}

Figure 3 gives the overall quality plotted as a function of storage time for all the samples during storage at $4^{\circ} \mathrm{C}$. The curves shown in the figure were obtained by the fitting to the experimental data, whereas the horizontal solid line is the sensory threshold. SAL values relative to the overall quality of product were listed in the second column of Table 1 for the investigated samples. These data were calculated only when the sensory attribute judgment was below 4 . As expected, the quality of tested readyto-cook meatloaf steadily decreased, regardless of the strategy adopted. As can be seen, no significant differences were observed between CNTMA (4.94 days) and EO-MA (5.38) samples, while they differed from SL60-MA (5.93) and SL-60-EO-MA (7.07) samples. The results obtained from sensorial evaluations showed that the organoleptic properties of the samples were not adversely affected by the treatments, making the product much more acceptable than the untreated samples. Although the use of $\mathrm{Na}$-lactate seemed to be beneficial for meat odor, this was counterbalanced by an undesirable discoloration. In particular, the color was the sensorial attribute that limited the overall quality of samples. Though other organic acids can be used as antimicrobials, lactate is successful as antimicrobial agent because it is known to enhance meat flavor due to the salty taste that it provides, while retaining color, and contributing to increase water 


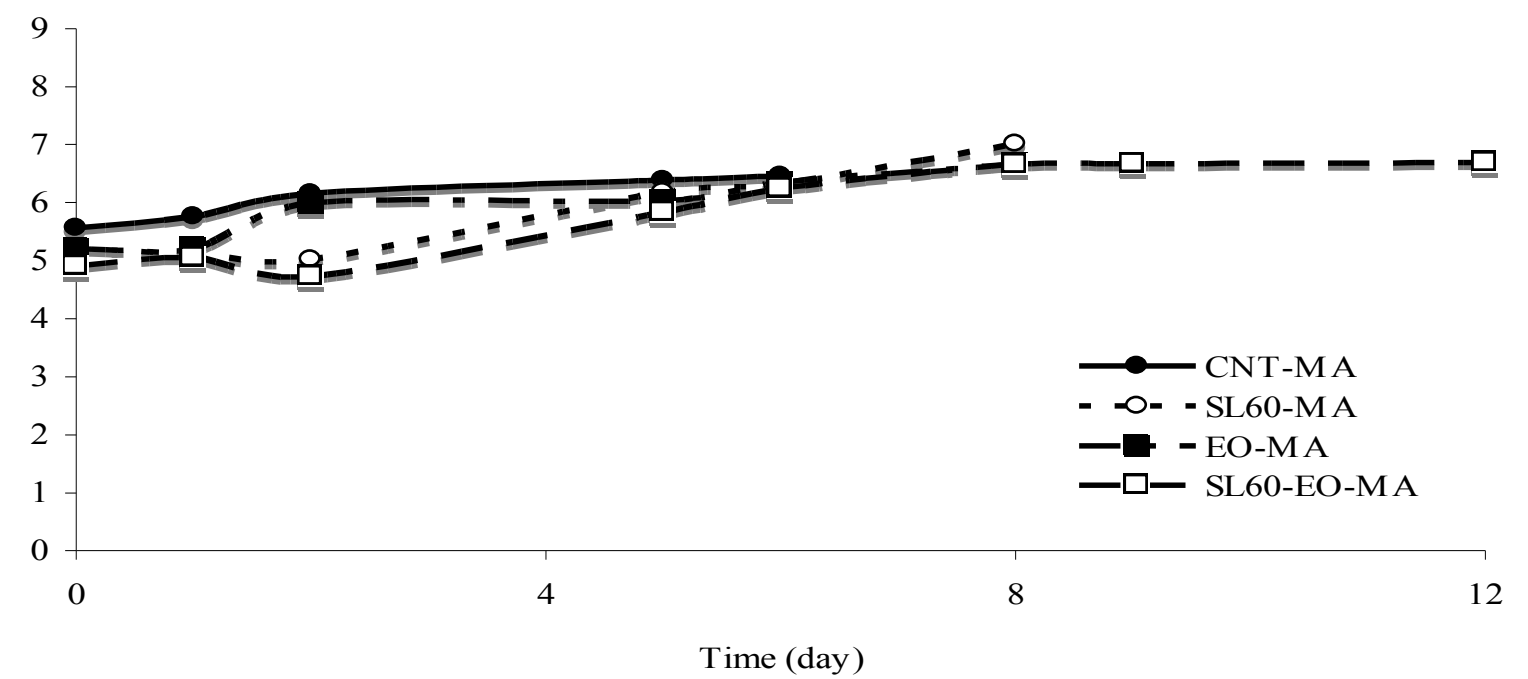

CNT-MA (control sample packaged in MAP); EO-MA (sample treated with essential oils, packaged in MAP); SL60-MA (sample treated with Na-lactate 60\%, packaged in MAP); SL60-EO-MA (sample treated with Na-lactate $60 \%$ and essential oils, packaged in MAP)

Figure 2: Evolution of $L A B$ during the storage time.

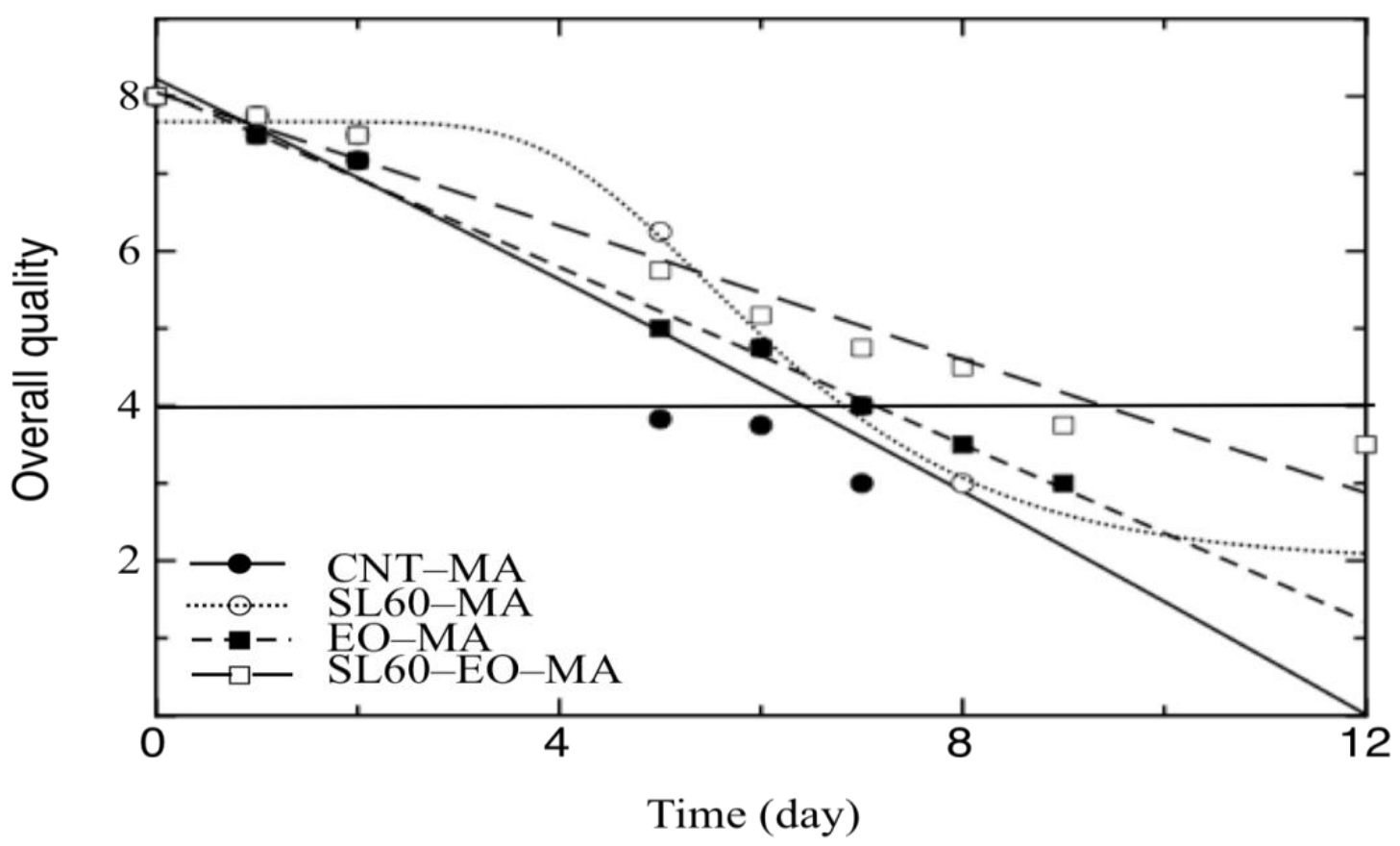

CNT-MA (control sample packaged in MAP); EO-MA (sample treated with essential oils, packaged in MAP); SL60-MA (sample treated with Na-lactate 60\%, packaged in MAP); SL60-EO-MA (sample treated with Na-lactate $60 \%$ and essential oils, packaged in MAP)

Figure 3: Evolution of the overall quality during the storage.

holding capacity [32]. Other researchers have also reported the benefits of Na-lactate on beef and pork flavor [21,23,33,34].

\section{Shelf life}

The shelf life values are also reported in Table 1. In the case under investigation, the shelf life of each tested sample was calculated as the lowest value between the MAL evaluated on the basis of TBA and the SAL on the basis of the overall quality. Sensory data were not in a very good agreement with microbiological data. As can be inferred from the table, for the CNT-MA and EO-MA samples, the proliferation of TBA 
represented the limiting factor for product acceptability, whereas, for the SL60-MA and SL-60-EO-MA treated with Na-lactate, the factor limiting shelf life was the sensorial quality. In particular, for SL60-MA and SL-60-EO-MA samples shelf life values more than 5 and 7 days, respectively, were obtained compared to the other samples for which shelf life values of about 3 days were reached. The percentage shelf life increase of each tested sample was also calculated, and values of $7.44 \%$, $110 \%$ and $150 \%$ were estimated for EO-MA, SL60-MA and SL-60EO-MA samples, respectively, when compared to the control. Results are in agreement to Ahmed et al. [35] who reported that the shelf-life of meats from freshly slaughtered sheep and goat carcasses at $5-7^{\circ} \mathrm{C}$ was extended after spraying the carcasses with a solution containing potassium sorbate, sodium acetate, sodium citrate, sodium lactate each at $2.5 \%$ and sodium chloride at $5 \%$.

\section{Conclusions}

Consumer's rising interest for ready-to-cook products has motivated researchers to standardize the processing process to give proper shelf life. The results of this study indicated that the combination of antimicrobial treatments and MAP slowed down microbial growth, allowed maintaining good sensory characteristics. In particular, the essential oils, Na-lactate and MAP inhibited the cell load of TAB, thus prolonging the microbiological stability. These findings suggest that it is advisable to implement additional measures, such as decontamination procedures, in order to prolong the shelf-life and increase the safety of this foodstuff.

\section{Acknowledgments}

This work was financially supported by Ministry of Economy and Finance Ministry of Education, University and Scientific Research and Technology and the Department of Budget and Planning Region Puglia by the program PON 0101409 - Process innovation and product to increase the safety profiles and to diversify the range of products ( fresh and cured) in pig meat ( SAFEMEAT).

\section{References}

1. Marshall DL, Bal'a MFA (2001) Microbiology of Meat. In: Hui YH, Ed. Meat Science and Applications, Marcel Dekker, Inc., CRC Press New York, USA.

2. Nychas GJE (1994) Modified atmosphere packaging of meat. In: Singh RP, Oliviera FAR (Eds) Minimal processing of foods and process optimization. An Interface CRC Press, London.

3. Fabrizio KA, Cutter CN (2005) Application of electrolyzed oxidizing water to reduce Listeria monocytogenes on ready-to-eat meats. Meat Sci 71: 327-333.

4. Hugas M, Garriga M, Monfort JM (2002) New mild technologies in meat processing: High pressure as a model technology. Meat Sci 62: 359-371.

5. Jimenez-Villarreal JR, Pohlman FW, Johnson ZB, Brown AHJR (2003) Effects of chlorine dioxide, cetylpyridinium chloride, lactic acid and trisodium phosphate on physical, chemical and sensory properties of ground beef. Meat Sci 65: 1055-1062.

6. Jimenez-Villarreal JR, Pohlman FW, Johnson ZB, Brown AHJR (2003) Lipid instrumental color and sensory characteristics of ground beef produced using trisodium phosphate, cetylpypiridinium chloride, chlorine dioxide or lactic acid as multiple antimicrobial interventions. Meat Sci 65: 885-891.

7. Karpińska-Tymoszczyk M (2011) The effect of water-soluble rosemary extract, sodium erythorbate, their mixture and packaging method on the quality of turkey meatballs. Int J Food Sci 23: 318-323.

8. Irkin R, Esmer OK (2013) Control of Listeria monocytogenes in ground chicken breast meat under aerobic, vacuum and modified atmosphere packaging conditions with or without the presence of bay essential oil at $4{ }^{\circ} \mathrm{C}$. Food Sci Technol Res 16: 285-290.

9. Zeitoun AAM, Debevere JM (1992) Decontamination with lactic acid/sodium lactate buffer in combination with modified atmosphere packaging effects on the shelf life of fresh poultry. Int J Food Microbiol 16: 89-98.

10. Gammariello D, Laverse J, Incoronato AL, Conte A, Contò F, et al. (2014) A multi-step optimisation approach to extend burger shelf life. Basic Res J Food Sci Tech 1: 15-28.

11. Gammariello D, Incoronato AL, Conte A, Del Nobile MA (2015) Use of sodium lactate and modified atmosphere packaging for extending the shelf life of ready-to-cook fresh meal. Packag Technol Sci 28: 101-112.

12. Houtsma PC, De Wit JC, Rombouts FM (1993) Minimum inhibitory concentration (MIC) of sodium lactate for pathogens and spoilage organisms occurring in meat products. Int J Food Microbiol 20: 247-257.

13. Del Nobile MA, Conte A, Cannarsi M, Sinigaglia M (2009) Strategies for prolonging the shelf life of minced beef patties. J Food Safety 29: 14-25.

14. Mastromatteo M, Incoronato AL, Conte A, Del Nobile MA (2011) Shelf life of reduced pork back-fat content sausages as affected by antimicrobia compounds and modified atmosphere packaging. Int J Food Microbiol. 150: $1-7$.

15. Das AK, Anjaneyulu ASR, Verma AK, Kondaiah N (2008) Effect of full-fat soy paste and soy granules on quality of goat meat patties. Int J Food Sci Tech 43: 383-392.

16. Smulders F (1987) Prospectives for microbial decontamination of meat and poultry by organic acids with special reference to lactic acid. In: Smulders FJM (Ed) Elimination of Pathogenic Organisms from Meat and Poultry Proceedings of the International Symposium : Prevention of Contamination, and Decontamina. Elsevier Science, Biomedical Division, London.

17. Van der Marel GM, Van Logtestijn JG, Mossel DA (1988) Bacteriological quality of broiler carcasses as affected by in-plant lactic acid decontamination. Int $J$ Food Microbiol 6: 31-42.

18. Bacus $\mathrm{J}$ (1989) Microbial control methods in fresh and processed meats. 41st Annual American Meat Science Association Reciprocal Meat Conference, Laramie, Wyoming.

19. Maas MR, Glass KA, Doyle MP (1989) Sodium lactate delays toxin production by clostridium-botulinum in cook-in-bag turkey products. Appl Environ Microb. 55: 2226-2229.

20. Incoronato AL, Gammariello D, Conte A, Del Nobile MA (2014) Technologica solutions to increase shelf life of fresh meat burger. J Food Process Pres.

21. Brewer MS, McKeith FK, Sprouls G (1993) Sodium lactate effects on microbial, sensory, and physical characteristics of vacuumpackaged pork sausage. $J$ Muscle Foods 4: 179-192.

22. Sameshima T, Takeshita K, Miki T, Arihara K, Itoh M, et al. (1997) Effect of sodium nitrite and sodium lactate on the growth of lactic acid spoilage bacteria isolated from cured meat products. Jpn J Food Microbiol 13: 159-164.

23. Papadopoulos LS, Miller RK, Acuff GR, Vanderzant C, Cross HR (1991) Effect of sodium lactate on microbial and chemical composition of cooked beef during storage. J Food Sci 56: 341-347.

24. Eckert LA, Maca JV, Miller RK, Acuff GR (1997) Sensory, microbial and chemical characteristics of fresh aerobically stored ground beef containing sodium lactate and sodium propionate. J Food Sci 62: 429-433.

25. Tan W, Shelef LA (2002) Effects of sodium chloride and lactates on chemical and microbiological changes in refrigerated and frozen fresh ground pork. Meat Sci. 62: 27-32.

26. Sallam KI, Samejima K (2004) Microbiological and chemical quality of ground beef treated with sodium lactate and sodium chloride during refrigerated storage. Lebensm Wiss Technol 37: 865-871.

27. Bingol EB, Bostan K (2007) Effect of sodium lactate on the microbiological quality and shelf life of sausages. Turk J Vet Anim Sci 31: 333-339.

28. Maca JV, Miller RK, Acuff GR (1997) Microbiological, sensory and chemica characteristics of vacuum-packaged ground beef patties treated with salts of organic acids. J Food Sci 62: 591-596.

29. Esmer OK, Irkin R, Degirmencioglu N, Degirmencioglu A (2011) The effects of modified atmosphere gas composition on microbiological criteria, colour and oxidation values of minced beef meat. Meat Sci 88: 221-226.

30. Jakobsen $\mathrm{M}$, Bertelsen $\mathrm{G}$ (2002) The use of $\mathrm{CO}_{2}$ in packaging of fresh red meats and its effect on chemical quality changes in the meat: A review. $J$ Muscle Foods 13: 143-168.

31. Mastromatteo M, Conte A, Del Nobile MA (2010) Combined use of modified 
Citation: Incoronato AL, Conte A, Gammariello D, Del Nobile MA(2015) Meatloaf with Semi-dry Vegetables: A Study of Processing and Preservation. J Food Process Technol 6: 470. doi:10.4172/2157-7110.1000470

Page 7 of 7

atmosphere packaging and natural compounds for food preservation. Food En Reviews 2: 28-38.

32. Doores S (2005) Organic acids. Antimicrobials in food. In: Davidson PM, Sofos JN, Branen AL Boca Raton, FL (Eds), CRC Press, Taylor and Francis Group.

33. Lamkey JW, Leak FW, Tuley WB, Johnson DD, West RL (1991) Assessment of sodium lactate addition to fresh pork sausage. J Food Sci 56: 220-223.
34. Sutton DS, Brewer MS, McKeith FK (1997) Effects of sodium lactate and sodium phosphate on the physical and sensory characteristics of pumped pork loins. J Muscle Foods 8: 95-100.

35. Ahmed SN, Chattopadhyay UK, Sherikar AT, Waskar VS, Paturkar AM, et al. (2003) Chemical sprays as a method for improvement in microbiological quality and shelf-life of fresh sheep and goat meats during refrigeration storage $\left(5-7^{\circ} \mathrm{C}\right)$. Meat Sci 63: 339-344 